\title{
P256: Survey of prevalence of healthcare associated infection in Chuyo Ouagadougou (Burkina Faso)
}

\author{
J Zoungrana*, A Traore, L Ouedraogo \\ From 2nd International Conference on Prevention and Infection Control (ICPIC 2013) \\ Geneva, Switzerland. 25-28 June 2013
}

\section{Introduction}

Nosocomial infections (NI) are now a major public health problem that is insufficiently known and poorly mastered in our health facilities. The management of these infections is part of a comprehensive approach to improving the safety and quality of patient care.

\section{Objectives}

To measure a point prevalence and describe the characteristics of nosocomial infections at the university hospital Yalagado and to analyze the anti-infective therapies.

\section{Methods}

First prevalence survey of nosocomial infections (NI) in two departments of medicine and three surgical services performed using a standardized questionnaire with data collection approved by department heads. The five services represent $40.46 \%$ of all service beds in the institution (295 beds) and 114 patients were included in the study.

\section{Definition criteria}

An infection is known as nosocomial if it was absent in a period of at least $48 \mathrm{~h}$ after admission to the hospital. Surgical site infections, were classified as nosocomial if infections occurred within 30 days following the surgery, or, in the year following the intervention in the case of the implementation of a prosthesis or implant.

\section{Results}

On the day of the survey, 27 of 114 patients were infected resulting in a prevalence of $23.7 \%$. In addition, $x$ patients were treated with anti-infective therapy is a prevalence of $\mathrm{x} \%$. Three locations accounted for $77.79 \%$ of NI: urinary tract infection (14.82\%), respiratory infection (18.52\%), surgical site infection (44.45\%). The prevalence of nosocomial infections varied according to the type of service (higher in surgery and intensive care) and patient characteristics.

\section{Conclusion}

Surveillance of nosocomial infections is a good way to educate health workers and to draw their attention to the local infectious epidemiology, allowing the development of preventive actions at the services.

\section{Disclosure of interest}

None declared.

Published: 20 June 2013

doi:10.1186/2047-2994-2-S1-P256

Cite this article as: Zoungrana et al.: P256: Survey of prevalence of healthcare associated infection in Chuyo Ouagadougou (Burkina Faso). Antimicrobial Resistance and Infection Control 2013 2(Suppl 1):P256. 